\title{
Fractional control of an offshore wind system
}

\author{
Rui Melicio ${ }^{a b}$ (IEEE Senior Member), Duarte Valério ${ }^{a}$, Victor M. F. Mendes ${ }^{b c d}$ \\ ${ }^{a}$ IDMEC, Instituto Superior Técnico, Universidade de Lisboa, Lisbon, Portugal \\ ${ }^{b}$ Departmento de Física, Escola de Ciências e Tecnologia, ICT, Universidade de Évora, Évora, Portugal \\ ${ }^{c}$ Department of Electrical Engineering and Automation, Instituto Superior de Engenharia de Lisboa, Lisbon, Portugal \\ ${ }^{d}$ CISE, Electromechatronic Systems Research Centre, Universidade da Beira Interior \\ Email: duarte.valerio@tecnico.ulisboa.pt,
}

\begin{abstract}
This paper presents a simulation on a way to improve the ability of an offshore wind system to recover from a fault in the rectifier converter. The system comprises a semi-submersible platform, a variable speed wind turbine, a synchronous generator with permanent magnets (PMSG), and a five-level multiple point diode clamped converter. The recovery is improved by shielding the DC link of the converter during the fault using as further equipment a redox vanadium flow battery. A fractional PI controller is used for the PMSG and the converter.
\end{abstract}

\section{INTRODUCTION}

Wind systems must cope with strict behaviour requirements regulated in grid codes, and in particular it is of great importance the recovery of normal operation in due time after a fault, avoiding eventual coming off from the electric grid. Furthermore, abnormal behaviour in the operation which is not avoided in due time can lead to a fault going into a failure, needing human intervention on the wind system, which in the case of offshore platforms is difficult and expansive. In this paper a fractional PI controller controls in simulation an offshore wind system where a vanadium redox flow battery (VRFB) [2] is used to store energy, and to replace during a short time span the delivery of energy coming from the generator interrupted by a fault in the rectifier converter [1], preserving the connection to the electric grid until the recovery of the full operation, and thus avoiding a failure implying the disconnection of the wind system [10]. The novelty herein presented is the usefulness of the VRFB.

\section{MOdEL}

The wind system comprises a the semi-submersible platform anchored to the seabed by suspended cables, a platform with a variable speed wind turbine (with power control by blade pitch angle), a synchronous generator with permanent magnets (PMSG), an MPC 5LC converter, and a VRFB. See Figure 1. Figure 2 shows the wind speed $u(t)$ and wave elevation $\eta(t)$ impacting the system. For model details see [10] and the references therein. Parameters are given in Table I.

TABLE I. WIND SYSTEM PARAMETERS

$\begin{array}{ll}\text { Turbine moment of inertia } & 5.5 \times 10^{6} \mathrm{kgm}^{2} \\ \text { Turbine rotor diameter } & 90 \mathrm{~m} \\ \text { Hub height } & 45 \mathrm{~m} \\ \text { Tip speed } & {[17.64,81.04] \mathrm{m} / \mathrm{s}} \\ \text { Rotor angular velocity } & {[6.9,31.6] \mathrm{rpm}} \\ \text { PMSG rated power } & 2000 \mathrm{~kW} \\ \text { PMSG inertia moment } & 400 \times 10^{3} \mathrm{kgm}^{2}\end{array}$

\section{A. Wind turbine}

The turbine mechanical power $P_{t}$ is given by [9]

$$
\begin{aligned}
P_{t} & =P_{t t}\left[1+\sum_{n=1}^{3} A_{n}\left(\sum_{m=1}^{2} a_{n m} g_{n m}(t)\right) h_{n}(t)\right] \\
g_{n m} & =\sin \left(\int_{0}^{t} m \omega_{n}\left(t^{\prime}\right) \mathrm{d} t^{\prime}+\varphi_{n m}\right)
\end{aligned}
$$

where $P_{t t}$ is given below in (25), $h_{n}$ is a modulation, the coefficients of the dynamics of the asymmetry of the turbine are

$$
\begin{aligned}
A_{1} & =0.01 \\
a_{11} & =\frac{4}{5} \\
a_{12} & =\frac{1}{5} \\
\omega_{1}(t) & =\omega_{t}(t) \\
\varphi_{11} & =0 \\
\varphi_{12} & =\frac{\pi}{2},
\end{aligned}
$$

the coefficients of the dynamics of the vortex tower interaction are

$$
\begin{aligned}
A_{2} & =0.08 \\
a_{21} & =\frac{1}{2} \\
a_{22} & =\frac{1}{2} \\
\omega_{2}(t) & =\omega_{t}(t) \\
\varphi_{21} & =0 \\
\varphi_{22} & =\frac{\pi}{2},
\end{aligned}
$$

the coefficients of the dynamics of the eigenswings in the blades are

$$
\begin{aligned}
A_{3} & =0.15 \\
a_{31} & =1 \\
\omega_{3}(t) & =\frac{1}{2}\left(g_{11}(t)+g_{21}(t)\right) \\
\varphi_{31} & =0,
\end{aligned}
$$

where $\omega_{t}(t)$ is the angular speed of the rotor. 


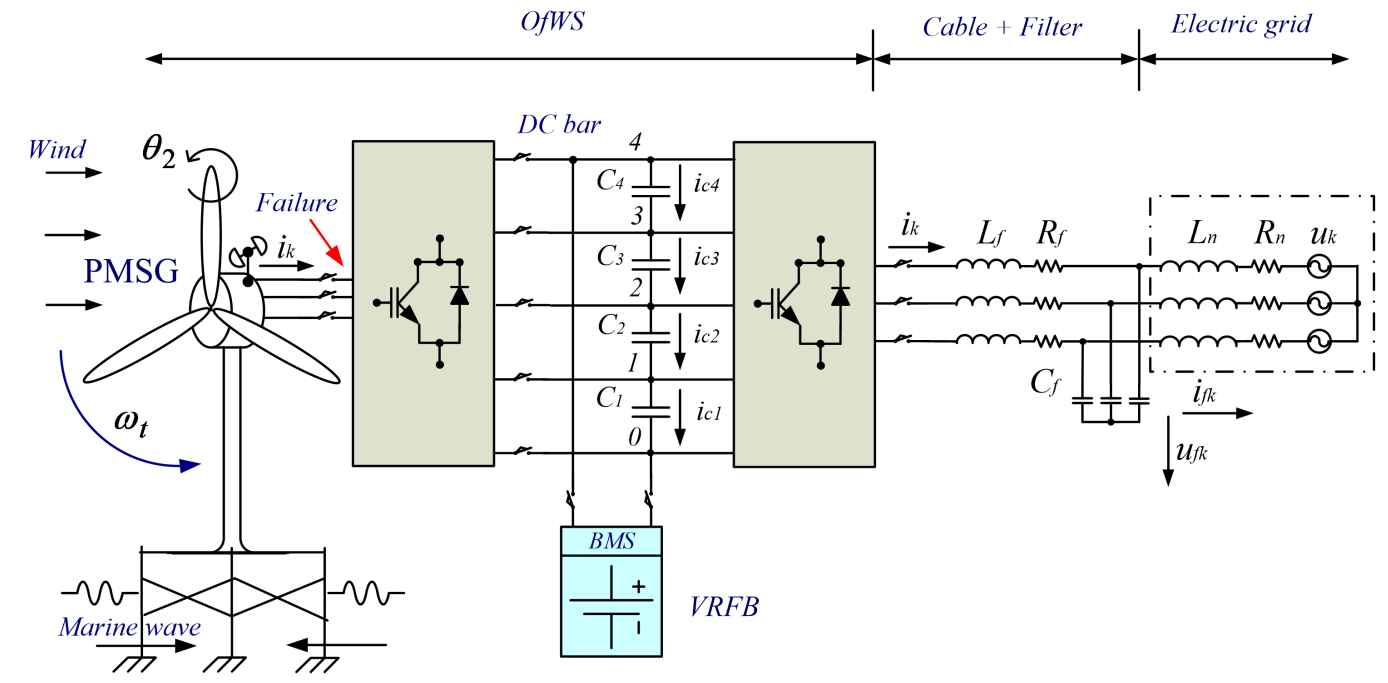

Fig. 1. Offshore wind system.

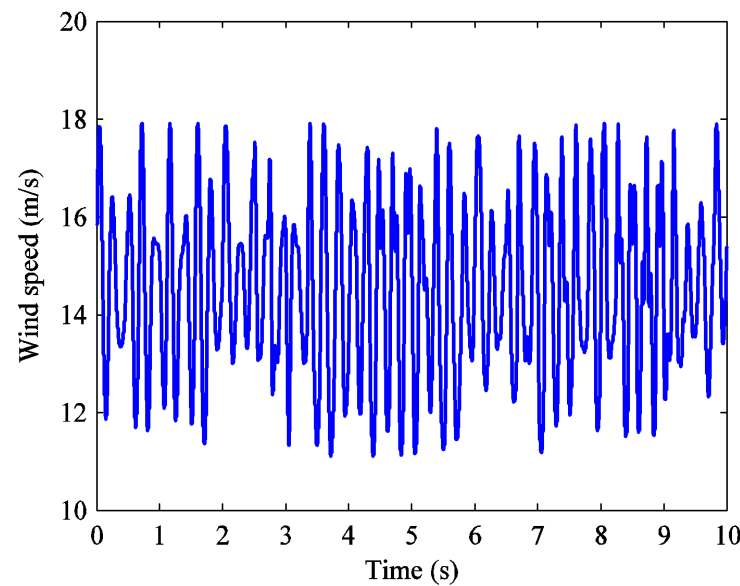

Fig. 2. Wind speed and wave elevation.

\section{B. Drivetrain}

Figure 3 shows the drivetrain model and the corresponding inertias, torques, springs and rotations; the three masses account for 1) the flexible part of the blade, 2) the rigid part of the blade part, hub, tower and floating platform, and 3) the PMSG. The equations are

$$
\begin{aligned}
\frac{\mathrm{d} \omega_{t}}{\mathrm{~d} t} & =\frac{1}{J_{b}}\left(T_{t}+T_{m s b}-T_{d b}-T_{b s}\right) \\
\frac{\mathrm{d} \omega_{h}}{\mathrm{~d} t} & =\frac{1}{J_{h}}\left(T_{t h}+T_{b s}+T_{m s h}-T_{d h}-T_{h s}\right) \\
\frac{\mathrm{d} \omega_{g}}{\mathrm{~d} t} & =\frac{1}{J_{g}}\left(T_{h s}+T_{m s g}-T_{d g}-T_{g}\right) \\
T_{m s b} & =k_{m s b} \omega_{w} \\
T_{m s h} & =k_{m s h} \omega_{w} \\
T_{m s g} & =k_{m s g} \omega_{w}
\end{aligned}
$$

The wind turbine mechanical power $P_{t t}$ has two components corresponding to the flexible and rigid segments of the blades

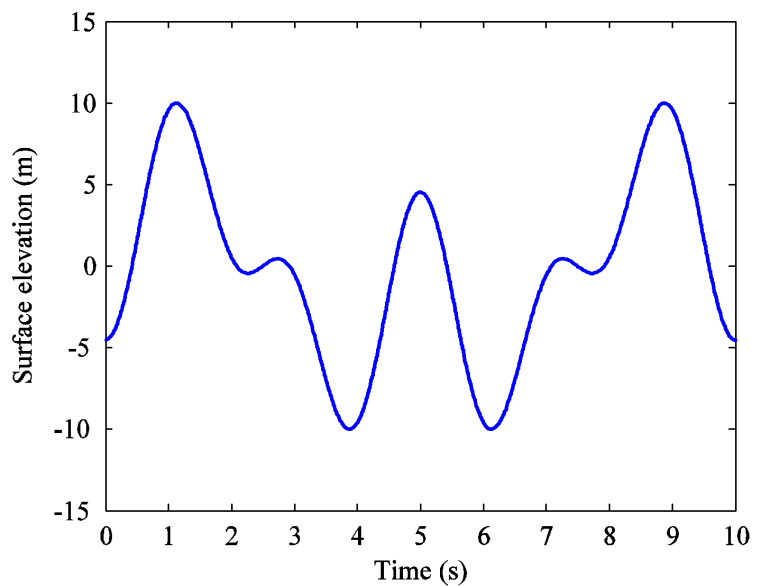

in the drive train:

$$
\begin{aligned}
P_{t t} & =P_{f b}+P_{r b} \\
P_{f b} & =\frac{1}{2} \rho \pi\left(R^{2}-r^{2}\right) u^{3} c_{p} \\
P_{r b} & =\frac{1}{2} \rho \pi r^{2} u^{3} c_{p}
\end{aligned}
$$

where $\rho$ is air density, $R$ is the radius of the area covered by the blades, $r$ is the radius of the area covered by the rigid part of the blades, and $c_{p}$ is a numerically calculated power coefficient [10].

\section{Generator and VRFB}

The generator is a PMSG modelled by standard equations found in the literature [3], [13]. To avoid demagnetisation of permanent magnet, a null reference stator direct component current is imposed [11]. The VRFB is a DC source with a value of $7.14 \mathrm{kV}, 2 \%$ plus of the DC link voltage. This type of source has significant discharge times [2]. 


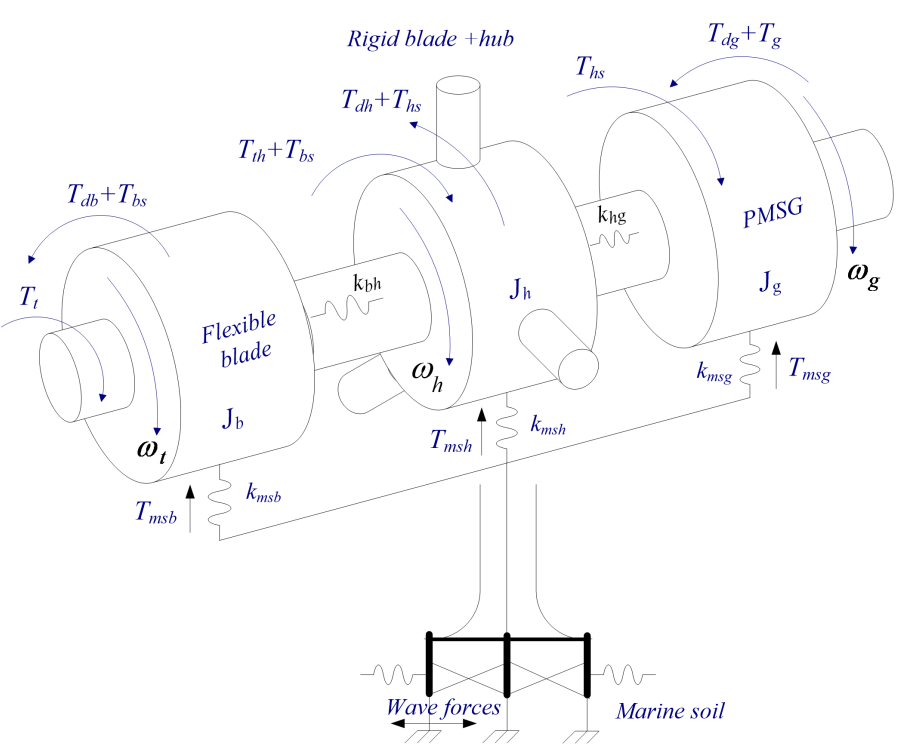

Fig. 3. Drivetrain and the variables of its model.

\section{Power converter}

Figure 4 shows the multiple point clamped five-level power converter (MPC 5LC) rectifier, that has 24 unidirectional commanded insulated gate bipolar transistors (IGBTs), considered ideal. An identical set of IGBTs is used for the inverter of the converter. Eight IGBTs connected on the same phase is branch $k$ of the converter. IGBTs are identified as $S_{i k}(k=1,2,3$ for the rectifier; $k=4,5,6$ for the inverter). The MPC 5LC equipped with the VRFB is shown in Fig. 4. The voltage level at each switching branch is

$n_{k}=\left\{\begin{array}{ccc}4, & \left(S_{5 k}, S_{6 k}, S_{7 k}, S_{8 k}\right)=1, & \left(S_{1 k}, S_{2 k}, S_{3 k}, S_{4 k}\right)=0 \\ 3, & \left(S_{4 k}, S_{5 k}, S_{6 k}, S_{7 k}\right)=1, & \left(S_{1 k}, S_{2 k}, S_{3 k}, S_{8 k}\right)=0 \\ 2, & \left(S_{3 k}, S_{4 k}, S_{5 k}, S_{6 k}\right)=1, & \left(S_{1 k}, S_{2 k}, S_{7 k}, S_{8 k}\right)=0 \\ 1, & \left(S_{2 k}, S_{3 k}, S_{4 k}, S_{5 k}\right)=1, & \left(S_{1 k}, S_{6 k}, S_{7 k}, S_{8 k}\right)=0 \\ 0, & \left(S_{1 k}, S_{2 k}, S_{3 k}, S_{4 k}\right)=1, & \left(S_{5 k}, S_{6 k}, S_{7 k}, S_{8 k}\right)=0\end{array}\right.$
$k=1,2 \ldots 6$

The combinations of the switching states which recognise the IGBTs state of blockage/conduction is established by the level variable $\delta_{j n_{k}}$, related to the charging state of each capacitor bank and given by

$$
\delta_{j n_{k}}=\left\{\begin{array}{ll}
0, & j>n_{k} \\
1, & j \leq n_{k}
\end{array}\right\}, k=1,2 \ldots 6
$$

The rectifier input voltage $u_{s k}, k=1,2,3$ and the inverter output voltage $u_{s k}, k=4,5,6$ are given by

$$
u_{s k}=\frac{1}{3} \sum_{j=1}^{p-1}\left(2 \delta_{j n_{k}}-\sum_{a=1, a \neq k}^{3} \delta_{j n_{a}}\right) U_{c j}
$$

The current $i_{c j}$ on each capacitor bank $C_{j}$ is given by

$$
i_{c j}=\sum_{k=1}^{3} \delta_{n k} i_{k}-\sum_{k=4}^{6} \delta_{n k} i_{k}
$$

The bar voltage $U_{d c}$ is given by

$$
\frac{\mathrm{d} U_{d c}}{\mathrm{~d} t}=\sum_{j=1}^{p-1} \frac{i_{c j}}{C_{j}}
$$

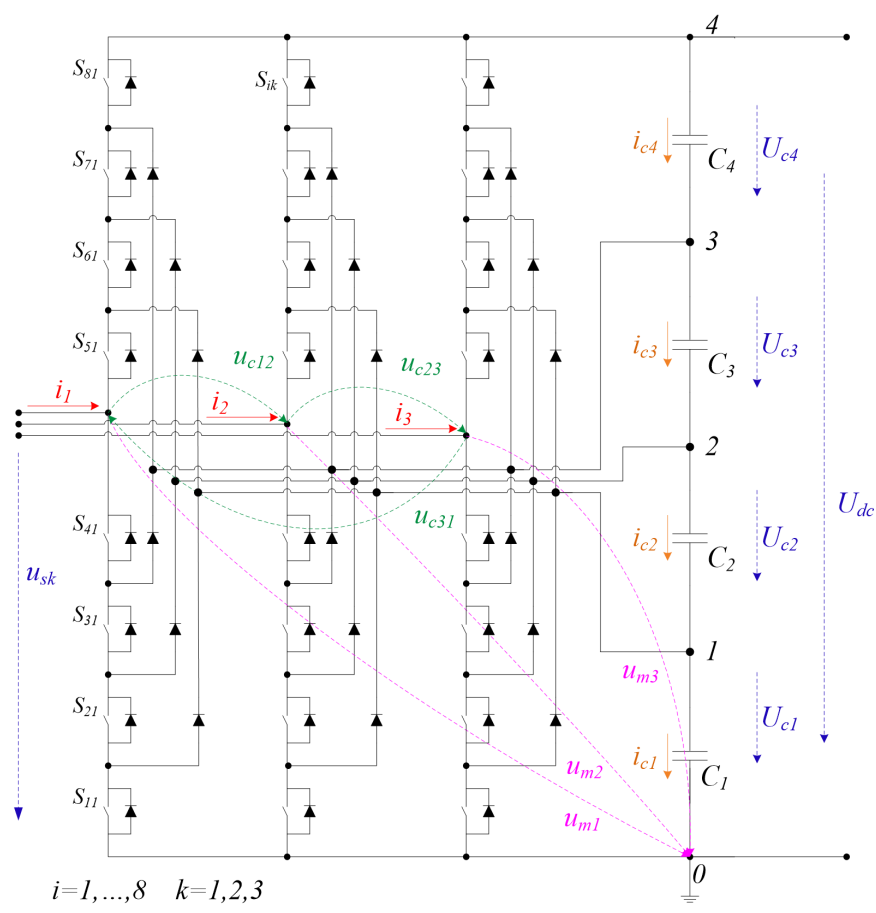

Fig. 4. MPC 5LC rectifier.

\section{E. Grid}

The current injected into the electric grid, which has $6 \mathrm{kV}$ at $50 \mathrm{~Hz}$, is given by

$$
\frac{\mathrm{d} i_{f k}}{\mathrm{~d} t}=\frac{1}{L_{n}}\left(u_{f k}-R_{n} i_{f k}-u_{k}\right), k=4,5,6
$$

\section{Simulations}

\section{A. Controller}

Fractional PID controllers were introduced by [7] and several tuning methods have been proposed, including tuning rules such as in [12] or numerical methods such as in [6]. A fractional PD controller given by

$$
C(s)=2.6+0.6 \frac{1}{s^{0.5}}
$$

was developed according to the method of [4]. The difference between the voltage $U_{d c}$ and the reference voltage $U_{d c}^{*}$ is numerically processed by the controller to determine a reference for the stator currents [8], [10] (see Figure 5; the Crone approximation was followed for implementation). The difference between the stator current and the reference stator current is corrected using sliding mode control; the final control action consists in pulse-width modulation by space vector modulation, since the IGBTs have on/off switching states. The required selection for the output voltage vector in 
the $(\alpha, \beta)$ space uses the discrepancy between the current of the stator and the reference current. This sliding mode control uses sliding surface $S\left(e_{\alpha \beta}, t\right)$, verifies stability conditions

$$
S\left(e_{\alpha \beta}, t\right) \frac{\mathrm{d} S\left(e_{\alpha \beta}, t\right)}{\mathrm{d} t}<0
$$

and leads to the output voltage vectors in the $(\alpha, \beta)$ space shown in Figure 6 (see sliding mode control details in [5]).

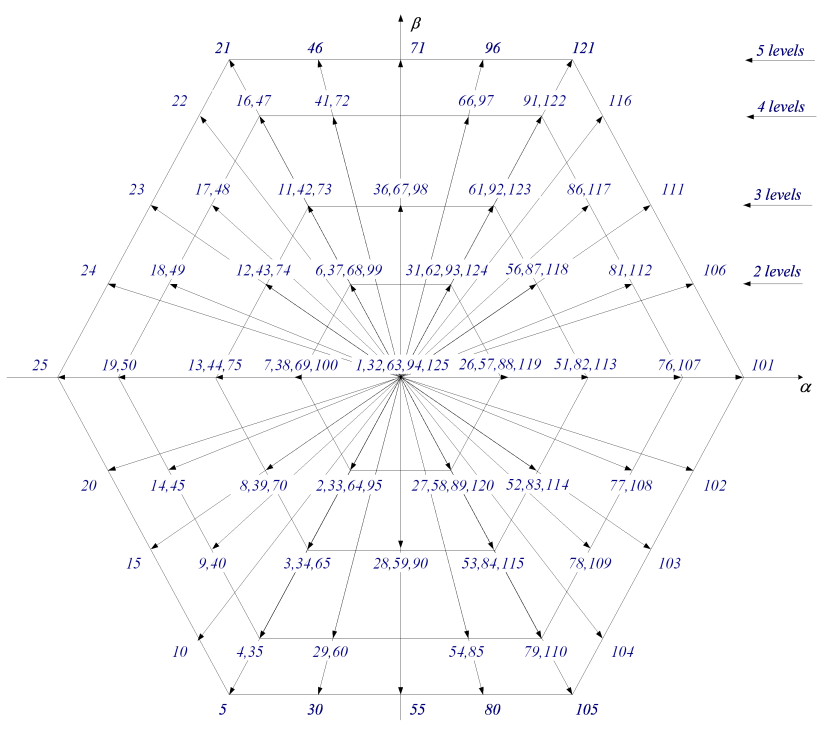

Fig. 6. Output voltage vectors for the 5LC.

\section{B. No fault}

Figure 7 shows the voltages and currents in the capacitors bank. The total harmonic distortion (THD) is 0.51 .

\section{Failure}

Suppose there is a fault in the rectifier, so that from $1.15 \mathrm{~s}$ to $1.65 \mathrm{~s}$ the capacitors are not charged. Figure 8 shows the voltages and currents in the capacitors bank. Voltages drop and currents have peaks: this unacceptable behaviour is a failure. Furthermore, the input voltages in the rectifier shown in Figure 9 do not recover even after $1.65 \mathrm{~s}$, because electric charges are not enough to sustain the drop on the voltages. Hence, the system is unable to maintain the interconnection with the electric grid, which is unacceptable.

\section{Ride through fault}

When the battery management system (BMS) is able to resort to the VRFB during the fault, the configuration of the system until it recovers is the one shown in Figure 10. The VRFB charges the capacitors, which are now able to sustain the drop on voltages, and thus normal operation is recovered after fault clearing. Figure 11 shows voltages and currents in the capacitors bank, which do not reach unacceptable values; Figure 12 shows input voltages and currents in the rectifier, proving that recovery is possible. The THD is now 0.54 , not significantly higher than the 0.51 value for the no fault case.

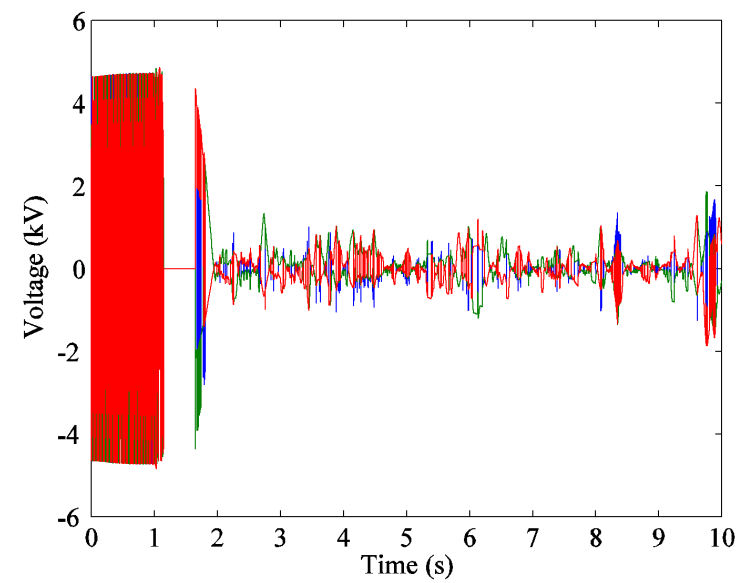

Fig. 9. Input voltages in the rectifier, when there is a fault.

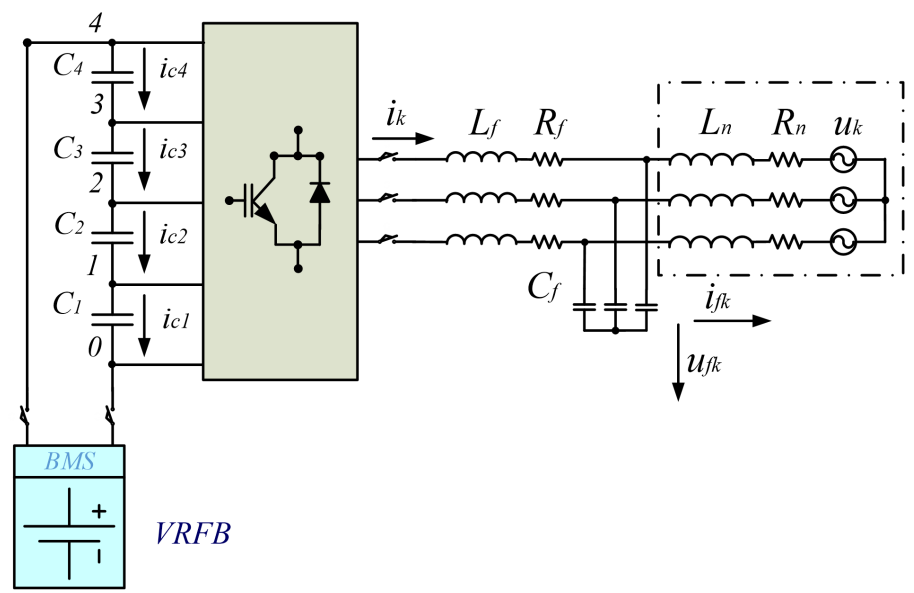

Fig. 10. Configuration of the wind system during the transient, resorting to the VRFB.

\section{CONCLUSION}

Simulations show that a fractional controller and a VRFB allow an offshore wind system to recover from a failure in the rectifier. Future work includes checking better fractional controller design methods for comparison (e.g. second generation Crone control) and testing these results experimentally.

\section{ACKNOWLEDGMENT}

This work was supported by FCT, through IDMEC, under LAETA, project UID/EMS/50022/2013 and European Union through the European Regional Development Fund, included in the COMPETE 2020 through the ICT project (UID/GEO/04683/2013) with the reference POCI010145FEDER007690.

\section{REFERENCES}

[1] B. N. Arribas, Rui Melicio, J. G. Teixeira, and V. M. F. Mendes. Vanadium redox flow battery storage system linked to the electric grid. In Proceedings of the International Conference on Renewable Energies and Power Quality, pages 1-6, Madrid, 2016. 


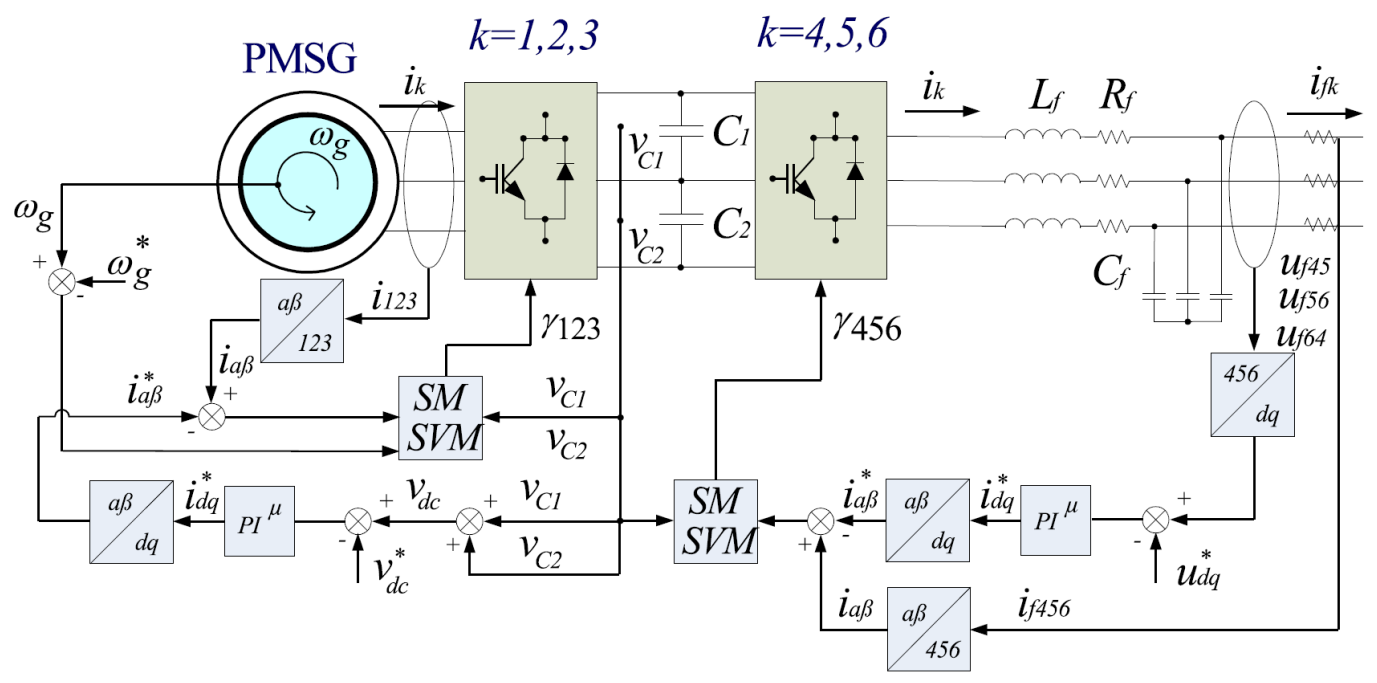

Fig. 5. Control scheme [8].
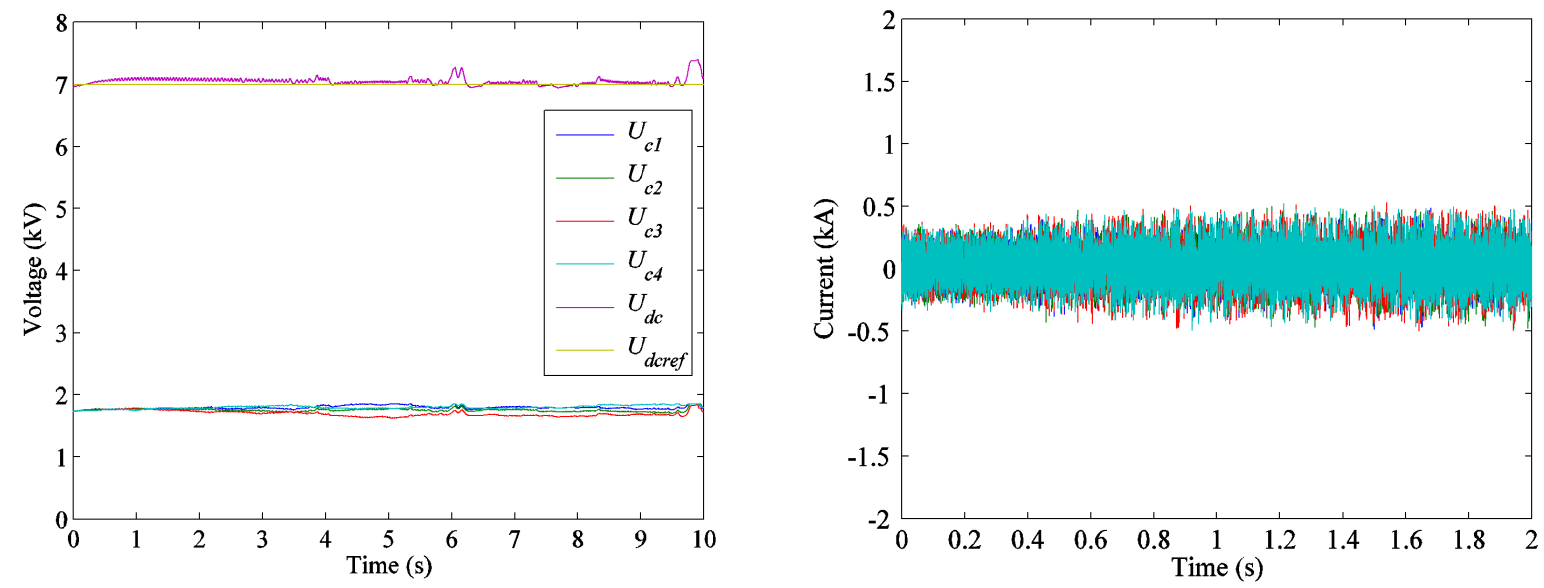

Fig. 7. Voltages and currents in the capacitors bank, when there is no fault.
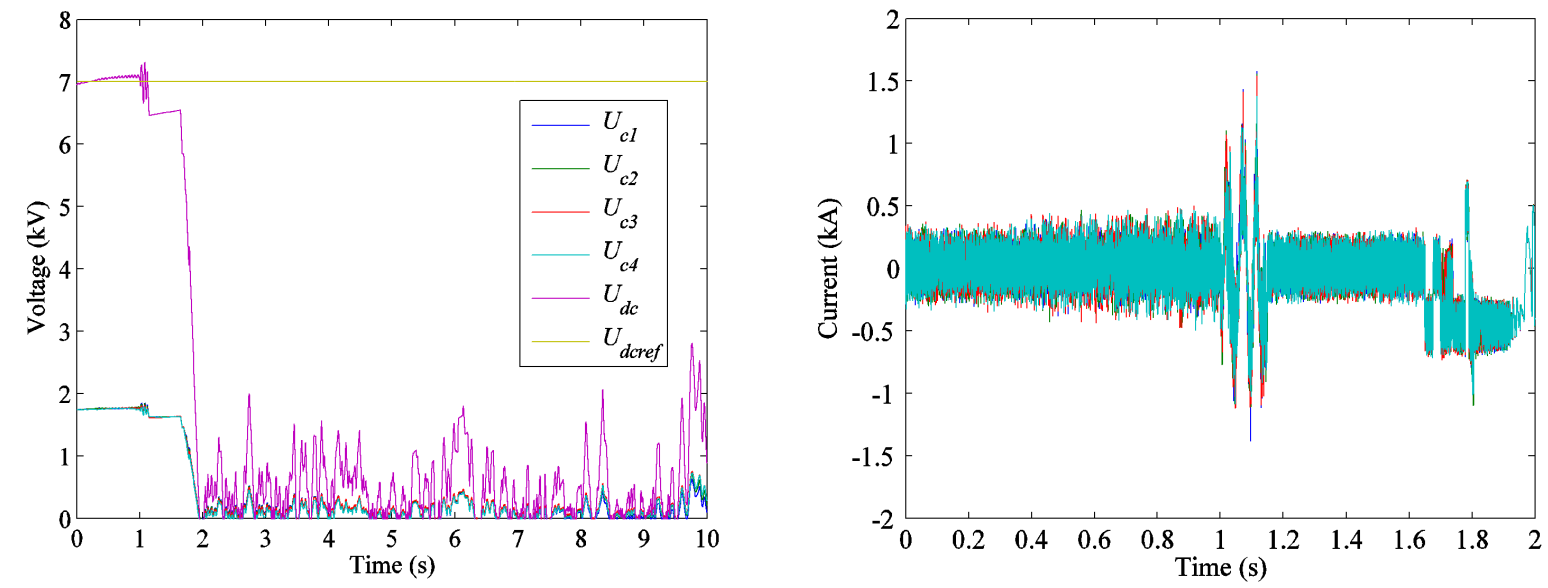

Fig. 8. Voltages and currents in the capacitors bank, when there is a fault in the rectifier. 

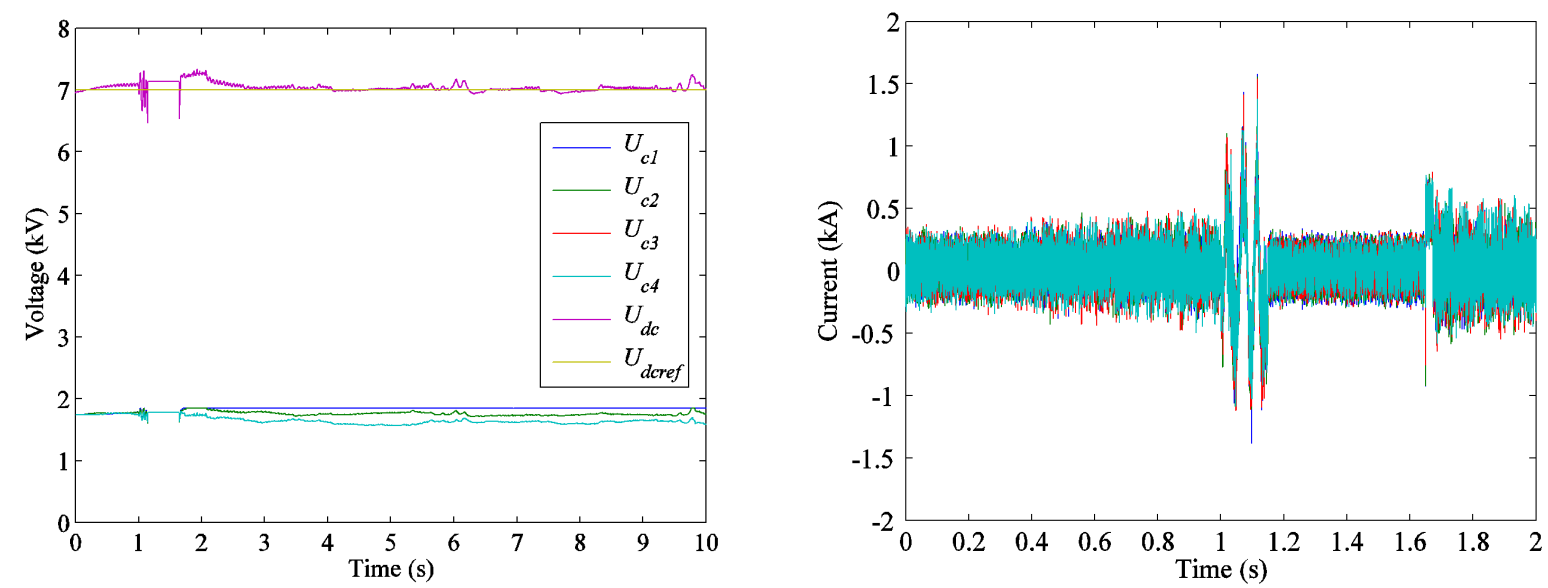

Fig. 11. Voltages and currents in the capacitors bank, when there is a fault in the rectifier and the BMS resorts to the VRFB.
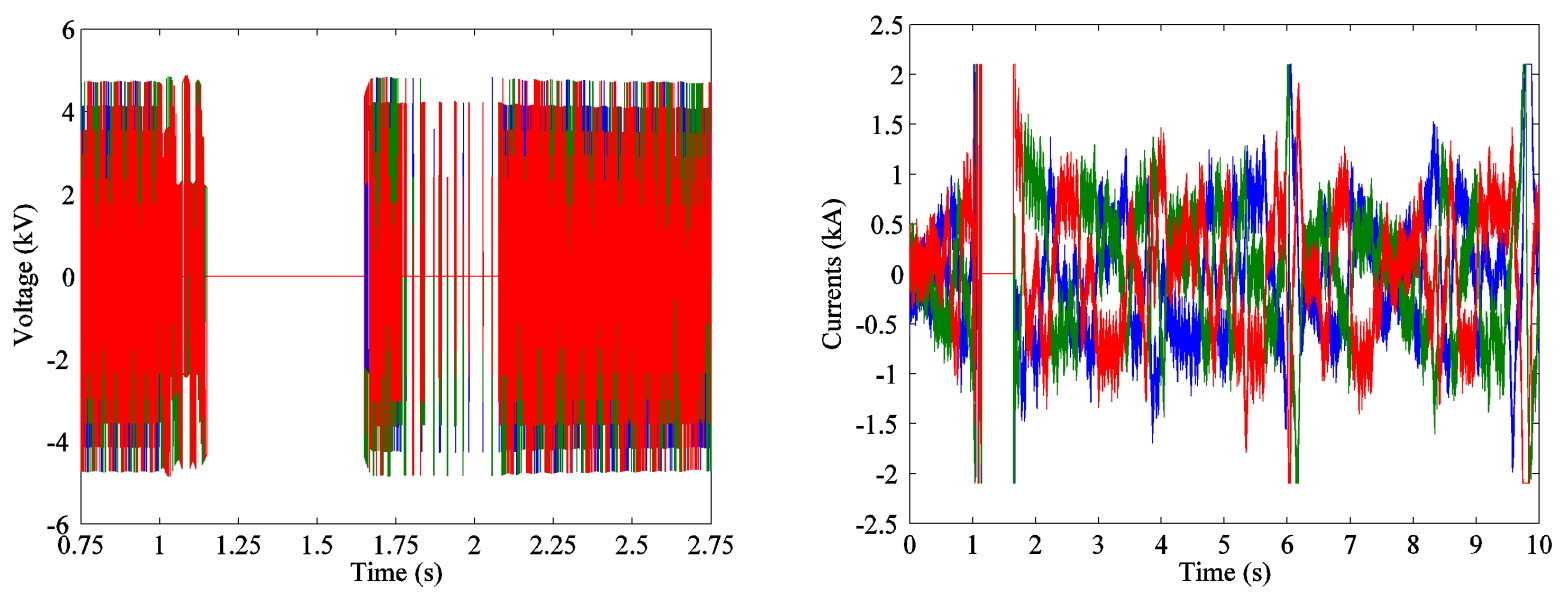

Fig. 12. Input voltages and currents in the rectifier, when there is a fault and the BMS resorts to the VRFB.

[2] Massimo Guarnieri, Paolo Mattavelli, and Giovanni Petrone. Vanadium redox flow batteries: potentials and challenges of an emerging storage technology. IEEE Industrial Electronics Magazine, 10(4):20-31, 2016.

[3] L. H. Holthuijsen. Waves in Oceanic and Coastal Waters. Cambridge University Press, Cambridge, 2007. p. 145-196.

[4] G. Maione and P. Lino. New tuning rules for fractional $p i^{\alpha}$ controllers. Nonlinear Dynamics, 49:251-257, 2007.

[5] Rui Melicio, V. M. F. Mendes, and J. P. S. Catal ao. A pitch control malfunction analysis for wind turbines with permanent magnet synchronous generator and full-power converters: proportional integral versus fractional-order controllers. Electric Power Components and Systems, 38(4):387-406, 2010.

[6] Concepción A. Monje, Blas M. Vinagre, Vicente Feliu, and YangQuan Chen. On auto-tuning of fractional order $\mathrm{PI}^{\lambda} \mathrm{D}^{\mu}$ controllers. In Fractional Differentiation and its Applications, Porto, 2006.

[7] I. Podlubny. Fractional differential equations: an introduction to fractional derivatives, fractional differential equations, to methods of their solution and some of their applications. Academic Press, San Diego, 1999.

[8] M. Seixas, Rui Melicio, and V. M. F. Mendes. Offshore wind turbine simulation: Multibody drive train. back-to-back NPC (neutral point clamped) converters. fractional-order control. Energy, 69:357-369, 2014.

[9] M. Seixas, Rui Melicio, and V. M. F. Mendes. Offshore wind energy system with DC transmission discrete mass: modeling and simulation. Electric Power Components and Systems, 44:2271-2284, 2016.

[10] M. Seixas, Rui Melicio, V. M. F. Mendes, and C. Couto. Blade pitch control malfunction simulation in a wind energy conversion system with MPC five-level converter. Renewable Energy, 89:339-350, 2016.

[11] T. Senjyu, S. Tamaki, N. Urasaki, and K. Uezato. Wind velocity and position sensorless operation for PMSG wind generator. In Proceedings of the 5th International Conference on Power Electronics and Drive Systems, pages 787-792, Singapore, 2003.

[12] Duarte Valério and José Sá da Costa. Tuning of fractional PID controllers with Ziegler-Nichols type rules. Signal Processing, 86(10):2771-2784, 2006

[13] L. Wang and D. N. Truong. Dynamic stability improvement of four parallel operated PMSG-based offshore wind turbine generators fed to a power system using a statcom. IEEE Transactions on Power Delivery, 28:111-119, 2013. 